\title{
Botanical Control of Citrus Green Mold and Peach Brown Rot on Fruits Assays Using a Persicaria acuminata Phytochemically Characterized Extract
}

\author{
Melina G. Di Liberto ${ }^{1,+}$, Gisela M. Seimandi ${ }^{2,+}\left(\mathbb{D}\right.$, Laura N. Fernández ${ }^{2}$, Verónica E. Ruiz ${ }^{2, *}$, Laura A. Svetaz ${ }^{1, *}$ \\ and Marcos G. Derita $1,2, * \mathbb{D}$ \\ 1 Farmacognosia, Facultad de Ciencias Bioquímicas y Farmacéuticas, Universidad Nacional de Rosario, \\ Suipacha 531, Rosario S2002LRK, Argentina; mdiliber@fbioyf.unr.edu.ar \\ 2 ICiAgro Litoral, Facultad de Ciencias Agrarias, Universidad Nacional del Litoral, CONICET, Kreder 2805, \\ Esperanza 3080HOF, Argentina; giselaseimandi@hotmail.com.ar (G.M.S.); \\ laurafernandez1@gmail.com (L.N.F.) \\ * Correspondence: vruiz@fca.unl.edu.ar (V.E.R.); lsvetaz@fbioyf.unr.edu.ar (L.A.S.); \\ mderita@fbioyf.unr.edu.ar (M.G.D.); Tel.: +54-93496-154-17342 (V.E.R.); +54-9341-153-061322 (L.A.S.); \\ +54-9341-155-317769 (M.G.D.) \\ + Contributed equally to this work and are co-first authors.
}

check for updates

Citation: Di Liberto, M.G.; Seimandi, G.M.; Fernández, L.N.; Ruiz, V.E.; Svetaz, L.A.; Derita, M.G. Botanical Control of Citrus Green Mold and Peach Brown Rot on Fruits Assays Using a Persicaria acuminata Phytochemically Characterized Extract. Plants 2021, 10, 425. https:// doi.org/10.3390/plants10030425

Academic Editor: Kirstin Wurms

Received: 29 December 2020

Accepted: 18 February 2021

Published: 24 February 2021

Publisher's Note: MDPI stays neutral with regard to jurisdictional claims in published maps and institutional affiliations.

Copyright: (c) 2021 by the authors. Licensee MDPI, Basel, Switzerland. This article is an open access article distributed under the terms and conditions of the Creative Commons Attribution (CC BY) license (https:/ / creativecommons.org/licenses/by/ $4.0 /)$.
Abstract: Persicaria acuminata (Polygonaceae) is a perennial herb that grows in the central area of Argentina and it is commonly used by native populations to heal infected wounds and other conditions related to fungal infections. In this article, we explored the in vitro antifungal activity of its ethyl acetate extract against a panel of three fruit phytopathogenic fungi including: Penicillium digitatum, P. italicum, and Monilinia fructicola. The sesquiterpenes isolated from the extract were also evaluated against these strains, demonstrating that the dialdehyde polygodial was the responsible for this activity. In order to encourage the use of the extract rather than the pure compound, we displayed ex vivo assays using fresh oranges and peaches inoculated with P. digitatum and $M$. fructicola, respectively, and subsequently treated by immersion with an extract solution of 250 and $62.5 \mu \mathrm{g} / \mathrm{mL}$, respectively. There were no statistically significant differences between the treatments with commercial fungicides and the extract over the control of both fruit rots. The concentration of the active compound present in the extract used on fruit experiments was determined by Gas Chromatography-Mass Spectroscopy. Finally, cytotoxicity evaluation against Huh7 cells showed that $P$. acuminata extract was less cytotoxic than the commercial fungicides at the assayed concentrations. After these findings we could conclude that a chemically characterized extract of $P$. acuminata should be further developed to treat fungal diseases in fruits from an agro-ecological model.

Keywords: phytopathogenic fungi; Persicaria acuminata; antifungal; fruits; orange; peach; rot; sesquiterpenes

\section{Introduction}

Plant diseases caused by phytopathogenic fungi are responsible for economic losses arising mainly from crop yield reduction, but also resulting from diminished product quality and safety; sometimes they also represent a risk for human and animal health due to food contamination and the accumulation of toxic residues in the environment. Due to market globalization and climate change, the problem is growing at an accelerated pace [1]. Since regulations on the use of new and existing fungicides are getting stricter, there is an urgent need to find and develop new chemical entities with antifungal activities [2]. Different naturally occurring compounds [3], semisynthetic derivatives [4], chitosan-based formulations [5], and plant products, including extracts [6] or essential oils [7], have been reported as part of this strategy. Moreover, some natural products and derivatives 
have been synthesized with the purpose of enlarging the offer of fungicides to be used on fruits [8].

Penicillium digitatum (Pers.) Sacc causes green mold rot disease, which is the most important post-harvest disease of citrus fruit worldwide. In predisposing conditions, losses may reach up to $90 \%$ of the crop [9]. Management of green mold is currently based on an integration of actions, such as minimizing fruit injury, sanitary practices, and treatments with fungicides [10]. The high number of pre- and post-harvest application of chemical fungicides has caused the development of $P$. digitatum resistant strains to several chemical groups [11]. Therefore, the requirement for alternative control strategies is increasing. The control of green mold without the application of chemical fungicides has been recently reviewed [11] and among these non-chemical treatments, natural compounds, irradiations, hot water treatments, salts, and biocontrol agents constitute promising strategies for $P$. digitatum management $[10,11]$.

Penicillium italicum Wehmer causes blue mold rot disease, and this pathogen is a major threat as it grows faster than $P$. digitatum at the same environmental conditions. Blue mold may also predominate in fruits treated with benzimidazoles, since resistance to these fungicides occurs more frequently in isolates of $P$. italicum compared to P. digitatum [11].

Monilinia fructicola (G. Wint.) Honey is the causal agent of brown rot, a destructive pathogen on stone fruits worldwide, which also causes blossom blight and twig cankers [12,13]. In peaches, $M$. fructicola is responsible for the main fruit losses during the growing season and the post-harvest stage, being reported in almost all producing regions worldwide [14]. The management of the disease integrates the application of fungicides with cultural handling, such as the removal of mummified fruits and the pruning of twigs with cankers to reduce inoculum levels. At present, the management of $M$. fructicola with fungicides constitutes a challenge for several reasons [15]. A high number of applications are required to protect flowers and fruits while taking into account the long susceptibility period for the infection. Fungicides such as dithiocarbamates, which present low possibilities to generate resistance, have long waiting periods that inhibit its application at fruit maturity. Other fungicides with shorter waiting periods, such as dicarboxamides, benzimidazoles, or demethylation inhibitors, have shown high risk of resistance build-up [15].

Persicaria acuminata (Kunth) M.Gómez syn. Polygonum acuminatum formerly belonged to Persicaria section of Polygonum genus, but since 2017 it is accepted named is P. acuminata [16]. This is a native herb that grows in Argentina whose vernacular name is "catay grande" and it is used in Traditional Medicine as an antiseptic [17]. A few studies regarding its biological activities had been published up to 2009, highlighting its insecticidal activity against Lutzomyia longipalis [18]. Moreover, phytochemical studies and antifungal activities against human pathogenic fungi for this species were carried out in our research group from 2010 [19-21], but this is the first report for its phytopathogenic fungi control. The aim of this work consisted of the in vitro antifungal evaluation of different extracts obtained from the aerial parts of P. acuminata and the isolation and identification of its active compounds. In addition, an ex-vivo test was carried out using a phytochemically characterized extract on post-harvested oranges and peaches, and finally the extract cytotoxicity was compared with that of the commercial fungicides that are being used. From the results, we could conclude that the fungicidal effect of the characterized extract obtained from $P$. acuminata did not show statistically significant differences with the commercial fungicides but it displayed lower phyto-toxicity than imazalil (Imz) and carbendazim (Cbz).

\section{Results}

2.1. In Vitro Antifungal Activities of P. acuminata Extracts and Compounds Isolated from Them against the Selected Phytopathogenic Fungi

The three extracts obtained from dried-leaves of P. acuminata were evaluated for their antifungal activities against $P$. digitatum, $P$. italicum, and $M$. fructicola using the micro broth dilution assay (Table 1). Figure 1 shows a picture of the plant species in its natural 
environment (A) and light microscopic photographs of the three phytopathogens under study (B-D).

Table 1. Minimum Inhibitory Concentrations (MIC) and Minimum Fungicidal Concentrations (MFC) $(\mu \mathrm{g} / \mathrm{mL})$ of extracts and pure compounds isolated from Persicaria acuminata against the selected post-harvest fruits pathogens.

\begin{tabular}{cccc}
\hline \multirow{2}{*}{ Sample } & \multicolumn{3}{c}{ MICs/MFCs $(\mu \mathrm{g} / \mathbf{m L})^{\mathbf{1}}$} \\
\cline { 2 - 4 } & P. digitatum & P. italicum & M. fructicola \\
\hline Hexanic extract & $500 / 1000$ & $500 / 1000$ & $125 / 250$ \\
EtOAc extract & $250 / 250$ & $500 / 500$ & $62.5 / 62.5$ \\
MeOH extract & I/I & I/I & I/I \\
Polygodial (1) & $125 / 125$ & $250 / 250$ & $31.25 / 31.25$ \\
Drimenol (2) & $\mathrm{I} / \mathrm{I}$ & $\mathrm{I} / \mathrm{I}$ & $\mathrm{I} / \mathrm{I}$ \\
Confertifolin $(\mathbf{3})$ & $\mathrm{I} / \mathrm{I}$ & $\mathrm{I} / \mathrm{I}$ & $\mathrm{I} / \mathrm{I}$ \\
Imazalil (Imz) & $7.8 / 7.8$ & $15.6 / 15.6$ & $0.97 / 0.97$ \\
Carbendazim $(\mathrm{Cbz})$ & $15.6 / 15.6$ & $15.6 / 15.6$ & $1.9 / 1.9$ \\
\hline
\end{tabular}

${ }^{1}$ Penicillium digitatum CCC-102; Penicillium italicum CCC-101; Monilinia fructicola INTA-SP345. The commercial fungicides Imazalil (Imz) and Carbendazim (Cbz) were used as positive controls. I: inactive (MIC or MFC > $1000 \mu \mathrm{g} / \mathrm{mL}$ for extracts or $>250 \mu \mathrm{g} / \mathrm{mL}$ for pure compounds).

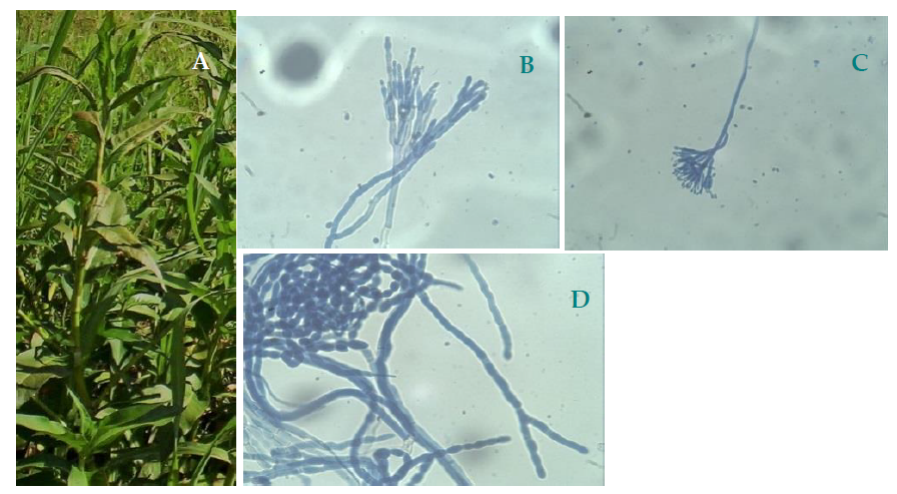

Figure 1. (A) Picture of the species Persicaria acuminata in its natural environment. Light microscopic photos $(40 \times)$ of the phytopathogens Penicillium digitatum (B), Penicillium italicum (C), and Monilinia fructicola (D). Both species of Penicillium show their characteristic conidiophores, fingershaped phialides and apical spores. Characteristic chains of lemon-shaped spores are observed for M. fructicola.

In addition, the three pure compounds isolated from the most active extract were assayed against the same fungal panel and the Minimum Inhibitory Concentrations (MIC) and the Minimum Fungicidal Concentrations (MFC) of all the extracts and compounds are shown in Table 1. Chemical structures of pure compounds are depicted in Figure 2.<smiles>CC1(C)CCC[C@]2(C)[C@@H](C=O)C(C=O)=CC[C@]12C</smiles>

(1)

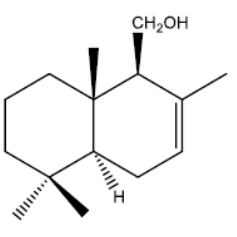

(2)<smiles>CC1(C)CCC[C@]2(C)C3=C(CCC12)C(=O)OC3</smiles>

(3)

Figure 2. Chemical structures of the compounds isolated from Ethyl Acetate extract of leaves of Persicaria acuminata. (1) Polygodial; (2) Drimenol; (3) Confertifolin.

Among the three phytopathogenic fungi selected for this work, the most sensitive to the fungicides evaluated here resulted to be M. fructicola. In contrast, both strains 
of Penicillium displayed higher MICs and MFCs values for all the samples evaluated, indicating that these microorganisms are very difficult to inhibit or kill (Table 1).

The hexanic extract showed moderate antifungal activity against the fungal panel, being remarkable the MIC and MFC displayed for M. fructicola (MIC 125 and MFC $250 \mu \mathrm{g} / \mathrm{mL}$, respectively). Ethyl acetate extract was the most active with MICs and MFCs between 62.5 and $500 \mu \mathrm{g} / \mathrm{mL}$, P. italicum being the most resistant microorganism. In contrast, methanolic extract was completely inactive for all the fungi tested here (Table 1).

Regarding the pure compounds, polygodial (1) showed the highest activity against the three phytopathogenic fungi, displaying MICs and MFCs from $31.25 \mu \mathrm{g} / \mathrm{mL}$ for $M$. fructicola to $250 \mu \mathrm{g} / \mathrm{mL}$ for $P$. italicum. Moreover, P. digitatum resulted moderately sensitive to this compound with MIC and MFC $=125 \mu \mathrm{g} / \mathrm{mL}$. The sesquiterpene alcohol drimenol (2) and the sesquiterpene lactone confertifolin (3) were completely inactive against this fungi panel.

\subsection{Detection of the Bioactive Compound in the Extracts by Bioautography}

The active extracts (hexanic and ethyl acetate), in addition with the pure compound $\mathbf{1}$ as a bioactive marker, were developed on a thin layer chromatography (TLC) plate and bioautographed using M. fructicola as test microorganism. The same TLC plate was performed without adding the fungal inoculum but exposed to UV lights of 254 and $365 \mathrm{~nm}$ and sprayed with $p$-anisaldehide sulphuric to chemically detect the presence of compound 1 in both extracts. Results showed that polygodial was present in the hexanic, as well as in the ethyl acetate extracts but in the latter, its concentration was higher (Figure 3). Therefore, it was corroborated that the bioactivity observed in these extracts is mainly attributed to the content of this active compound.

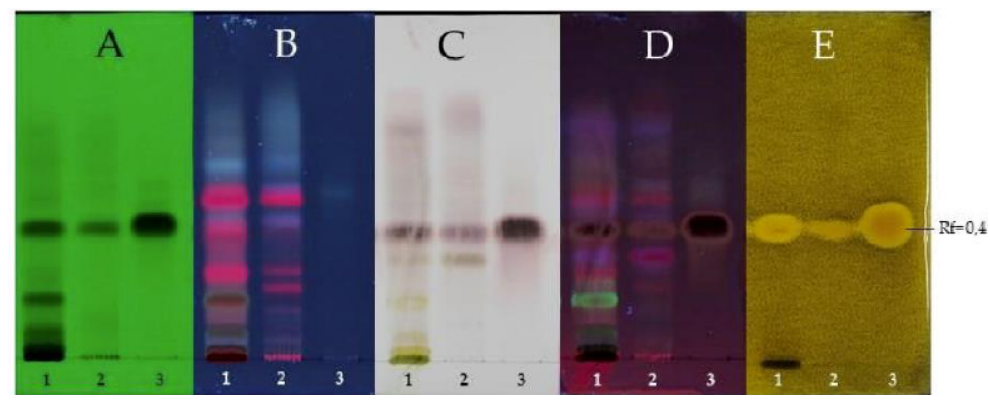

Figure 3. Thin Layer Chromatography developed for EtOAc extract of P. acuminata (1), hexanic extract of $P$. acuminata (2) and the pure compound polygodial (3: $\mathrm{Rf}=0.4)$. (A) exposed to UV light $254 \mathrm{~nm}$; (B) exposed to UV light $365 \mathrm{~nm}$; (C) sprayed with $p$-anisaldehide sulphuric; (D) sprayed wih p-anisaldehide sulphuric and exposed to UV light $365 \mathrm{~nm}$; (E) bioautography using M. fructicola as tested microorganism. Mobile phase: Hexane:EtOAc (7:3).

\subsection{Quantification of the Bioactive Compound in the EtOAc Extract of P. acuminata}

Taking into account the variability of bioactive compounds concentrations in the complex mixture constituted by the extract and with the aim of characterizing the concentration of polygodial in the extract that was used to perform these assays; GC-EM techniques were applied. The calibration function was obtained by two-fold dilution solutions (from $500 \mu \mathrm{g} / \mathrm{mL}$ to $125 \mu \mathrm{g} / \mathrm{mL}$ ) of pure compound correlated with the parameter Total Ion Chromatogram (TIC) area. Table 2 shows the values obtained for the three points of dilutions and the correspondent TIC areas as well as for the extract solution of $1000 \mu \mathrm{g} / \mathrm{mL}$.

Validation parameters for the quantitative assessment of polygodial are depicted in Tables 3 and 4, indicating linear regression data, Limit of Detection (LOD) and Limit of Quantification (LOQ), as well as intra- and inter-day precision of polygodial detection. 
Table 2. Total Ion Chromatogram areas obtained for the two-fold diluted solutions of pure polygodial (from 500 to $125 \mu \mathrm{g} / \mathrm{mL}$ ) and the extract solution $(1000 \mu \mathrm{g} / \mathrm{mL}$ ) using Gas Chromatography-Mass Spectroscopy. Experiments were done by triplicate.

\begin{tabular}{cc}
\hline Pure Polygodial Concentration $(\mu \mathrm{g} / \mathrm{mL})$ & TIC Areas \\
\hline 500 & $1.61 \times 105$ \\
250 & $7.97 \times 104$ \\
125 & $1.34 \times 104$ \\
EtOAc extract of $P$. acuminata $(\mathbf{1 0 0 0} \mu \mathrm{g} / \mathrm{mL})$ & TIC area \\
130 & $5.22 \times 104$ \\
\hline
\end{tabular}

Table 3. Linear regression data, limit of detection (LOD) and limit of quantification (LOQ) of polygodial detection.

\begin{tabular}{cccccc}
\hline & \multicolumn{2}{c}{ Linear Regression Data } & \multicolumn{2}{c}{ Limits } \\
\cline { 2 - 6 } & $\begin{array}{c}\text { Regression } \\
\text { Equation }\end{array}$ & $\boldsymbol{R}^{\mathbf{2}}$ & $\begin{array}{c}\text { Linear Range } \\
(\mu \mathrm{g} / \mathrm{mL})\end{array}$ & $\begin{array}{c}\text { LOD } \\
(\mu \mathrm{g} / \mathrm{mL})\end{array}$ & $\begin{array}{c}\text { LOQ } \\
(\mu \mathrm{g} / \mathrm{mL})\end{array}$ \\
\hline Polygodial & $\mathrm{y}=91400 \mathrm{x}-113.2$ & 0.996 & $1000-31.2$ & 0.008 & 0.023 \\
\hline
\end{tabular}

Table 4. Intra- and inter-day precision of polygodial.

\begin{tabular}{cccc}
\hline & \multicolumn{3}{c}{ Precision } \\
\hline & $\begin{array}{c}\text { Concentration } \\
(\mu \mathrm{g} / \mathrm{mL})\end{array}$ & $\begin{array}{c}\text { Intra-Day }(n=3), \\
\text { RDS \% }\end{array}$ & $\begin{array}{c}\text { Inter-Day }(n=3) \\
\text { RDS \% }\end{array}$ \\
\hline \multirow{3}{*}{ Polygodial } & 28.00 & 2.1 & 2.4 \\
& 14.00 & 2.1 & 2.0 \\
& 1.00 & 2 & 2.3 \\
\hline
\end{tabular}

Results showed that the concentration of the bioactive compound polygodial in the extract used to carry out the assays for the control of the corresponding disease on fruits was $130 \mu \mathrm{g} / \mathrm{mg}$ of dry extract. Moreover, the same extract was used for the cytotoxicity evaluation and therefore, the same concentration of the bioactive compound determined the results of cellular viability.

\subsection{Effect of Etoac Extract of P. acuminata for the Control of Citrus Green Mold and Peach Brown Rot on Fresh Fruits}

The effect of the most active extract of P. acuminata was examined ex-vivo on fresh harvested oranges cv. 'Salustiana' infected with $P$. digitatum, where the wound-inoculated fruits were treated with the bioactive extract by dipping in a $250 \mu \mathrm{g} / \mathrm{mL}$ solution and using $\operatorname{Imz}(7.8 \mu \mathrm{g} / \mathrm{mL})$ as commercial fungicide for comparison. After 14 days of the treatment applications, no significant differences on the number of fruits and disease severity were observed for both treatments (P. acuminata EtOAc extracts (Figure 4A) and Imz (Figure 4B)). The control fruits (those which had been only inoculated with the pathogen, but not treated with any fungicide (Figure 4C)) showed noticeable symptoms of the disease caused by the pathogen (see the number of sporulation index in each fruit which is described in Section 4.4.3). Both treatments (P. acuminata EtOAc extract and Imz) reduced significantly $(p=0.03)$ green mold sporulation index with respect to the control oranges, showing no significant differences between them. 

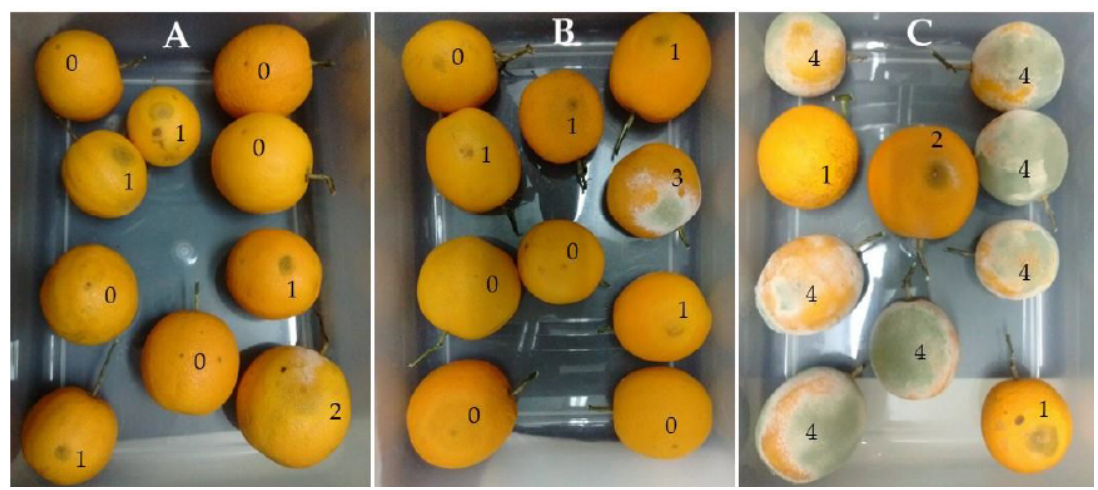

Figure 4. Pictures showing P. digitatum sporulation index (0 to 4 scale, in which the value 0 was assigned to negligible sporulation and 4 referred to a dense fungal sporulation over the entire fruit) on wound-inoculated oranges treated with Persicaria acuminata EtOAc extract (A), commercial imazalil fungicide (Imz), (B) and the control set, (C) without any treatment.

A similar trial was also carried out on fresh peaches cv. 'Red Globe' but infected with the phytopathogen $M$. fructicola. The commercial product $\mathrm{Cbz}$ was applied as negative control for the determination of the sporulation index of infected fruits (see Section 4.4.3). As an alternative treatment, $P$. acuminata EtOAc extract was applied to wound-inoculated peaches by immersion in a $62.5 \mu \mathrm{g} / \mathrm{mL}$ solution of the extract. A control group of fruits without antifungal agents was also used. After 10 days of applying the treatments, it was observed that the untreated group exhibited severe symptoms of the fungal disease, which led to discard the whole lot of fruits. Additionally, the set of fruits treated with Cbz or P. acuminata EtOAc extract indicated clearly that both of them had protected the fruits by significantly reducing the brown rot sporulation index (Figure 5A-C). In addition, examination of the set of peaches treated with P. acuminata EtOAc extract revealed that less fruits showed symptoms of fungal infection while those exposed to commercial $\mathrm{Cbz}$ appeared to be infected in a greater degree. Furthermore, despite no significant difference was observed between the fruits treated with the commercial fungicide and those treated with the alternative one proposed in this work, the results suggested that the latter could be even more powerful than the commercial agent. This requires further investigations.
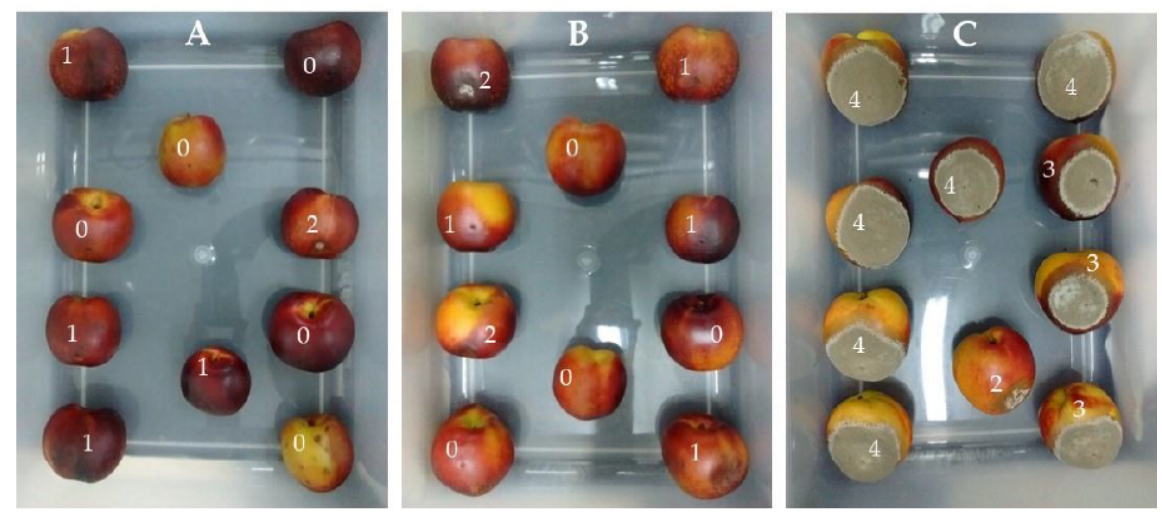

Figure 5. Pictures showing $M$. fructicola sporulation index ( 0 to 4 scale, in which the value 0 was assigned to negligible sporulation and 4 referred to a dense fungal sporulation over the entire fruit) on wound-inoculated peaches treated with Persicaria acuminata EtOAc extract (A), commercial Carbendazim (B) and the control set, (C) without any treatment.

\subsection{Cytotoxicity Evaluation of P. acuminata EtOAc Extract Compared with Commercial Fungicides}

As shown in Figure 6, the viability of Huh7 cells was $76.27 \pm 2.86 \%, 45.74 \pm 3.08 \%$ and $41.74 \pm 2.07 \%$ in the presence of P. acuminata EtOAc extract, Cbz and Imz, respectively, at 
their MICs values (2-fold dilutions). This means that the extract seems to be less cytotoxic than commercial antifungals at the concentrations evaluated by this method, since the higher cellular viability values means lower cytotoxicity. Notice that the abscissa axis shows the serial dilutions from the most concentrated sample solutions (dilutions 1), which are twice as concentrated as their MIC values (2-fold dilutions), and so on. Therefore, 4-fold dilutions are represented as the most dilute solutions of each sample, and they present the highest cellular viability.

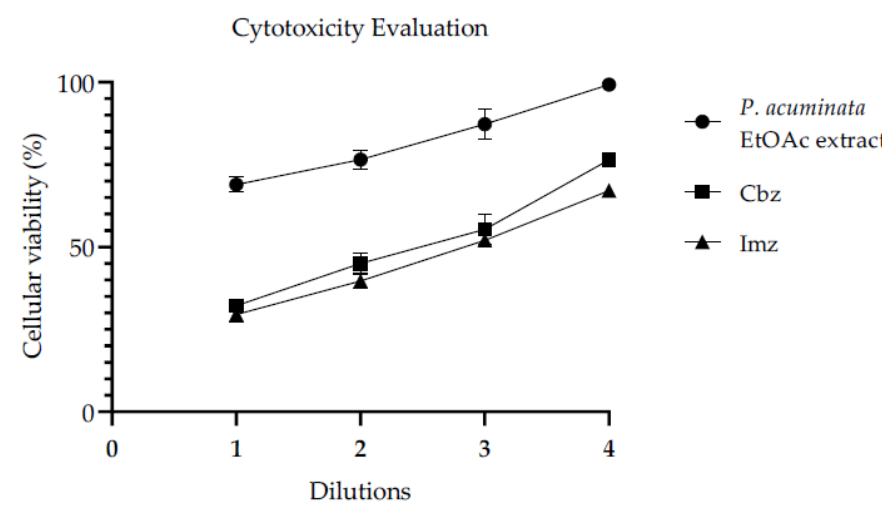

Figure 6. Cellular viability of Huh7 cells in the presence of $P$. acuminata EtOAc extract and commercial fungicides $\mathrm{Cbz}$ and Imz at different concentrations: Dilutions 1, 2, 3, and 4 correspond to $2 \times, 1 \times$, $\frac{1}{2} \times$, and $\frac{1}{4} \times$ MIC, respectively. Values are expressed as mean \pm SD, determined by triplicate.

\section{Discussion}

In this work, we explored the in vitro antifungal activity of different extracts obtained from the leaves of P. acuminata. The ethyl acetate extract showed the highest bioactivity against a panel of three fruit phytopathogenic fungi including: P. digitatum, P. italicum, and M. fructicola. The sesquiterpenes isolated from the extract were also evaluated against these fungal strains, demonstrating that the dialdehyde polygodial was the responsible for this activity. In order to encourage the use of the extract rather than the pure compound, we displayed ex vivo assays using fresh oranges and peaches inoculated with P. digitatum and M. fructicola, respectively, and subsequently treated by immersion with an extract solution of 250 and $62.5 \mu \mathrm{g} / \mathrm{mL}$. There were no statistically significant differences between the treatments with the commercial fungicides and the extract over the control of both fruit rots. The concentration of the active compound present in the extract used on fruit experiments was determined by GC-MS, resulting in $130 \mu \mathrm{g} / \mathrm{mg}$ of dry extract. Finally, cytotoxicity evaluation against Huh7 cells showed that P. acuminata extract was less cytotoxic than the commercial fungicides at the assayed concentrations.

The genus Polygonum (Polygonaceae) has been widely studied from a phytochemical point of view and by its interesting bioactivities. The genus includes approximately 300 species that are widely distributed in temperate regions of the world, but since most of them grow in China, many reviews describing the 113 species used in the traditional Chinese medicine appear in the literature [22]. Phenolic compounds from P. cuspidatum and $P$. bistorta demonstrated cytotoxicity against different type of cancer cells while their stilbenes and anthraquinones are potent anti-oxidants. These last type of compounds, but isolated from P. aviculare and P. glabrum, showed a broad antibacterial range (Gram-positive and Gram-negative), as well as antifungal properties [22]. A methanolic extract of P. maritum collected from the Argelian coast proved to be active against Bacillus cereus, B. subtilis, and Staphylococcus aureus, probably due to its high content of phenolic compounds. Moreover, the crude methanolic extract obtained from $P$. viscosum leaves was as anthelminthic as standard drugs [22]. Seeds of P. equisetiforme collected from different regions of Tunisia were characterized for the presence of unsaturated fatty acids, flavonoids and tannins, which were strong 2,2-diphenyl-1-picrylhydracil (DPPH) scavengers, highlighting the nutritive value of these seeds as antioxidants and the source of bioactive compounds [23]. 
The native Argentinian herb Persicaria acuminata syn. Polygonum acuminatum had been reported previously for its antifungal properties against the human fungal pathogens Candida albicans, C. tropicalis, Cryptococcus neoformans, and the dermatophytes Trichophyton mentagrophytes, T. rubrum, and Microsporum canis with MICs and MFCs between 15.6 and $62.5 \mu \mathrm{g} / \mathrm{mL}$ according the Clinical \& Laboratory Standards Institute techniques [24]. In the same article, a seasonal variation study demonstrated that dichloromethane extracts of $P$. acuminata leaves collected in autumn had the highest content of polygodial and the lowest MICs against the fungi tested, being the most suitable for treating conditions related to fungal infections in humans [19]. Based on this knowledge, we directed our new lines of investigations towards the control of fruit phytopathogenic fungi with the aim of applying active extracts or compounds in fresh fruit experiments. In this work, we demonstrated that EtOAc extract of P. acuminata was the most active against the phytopathogens $P$. digitatum, P. italicum, and M. fructicola (MICs and MFCs between 62.5 and $1000 \mu \mathrm{g} / \mathrm{mL}$ ), being much less active than against human pathogens, as reported by Derita et al. (2009) [19]. Moreover, methanolic extract was inactive in accordance with the previous results [19]. The three sesquiterpenes (polygodial, drimenol, and confertifolin) were isolated from the most active extract, but in contrast with the previous work $[19,21]$ only polygodial showed activity against the phytopathogens evaluated here, demonstrating by bioautography that this compound was the bioactive marker for the EtOAc extract. Additionally, its anti-phytopathogenic activities (MICs and MFCs between 31.25 and $250 \mu \mathrm{g} / \mathrm{mL}$ ) were lower than those displayed against human pathogens (MICs and MFCs between 3.9 and $62.5 \mu \mathrm{g} / \mathrm{mL}$ ), indicating the difficulty of the eradication of this type of filamentous fungi.

Many sesquiterpenes obtained from another plant source (Drimys winteri Forst) have been reported against phytopathogens in vitro [6,25]. Particularly, Montenegro et al. (2018) reported high MICs values (from 16 to $32 \mu \mathrm{g} / \mathrm{mL}$ ) for the sesquiterpenes polygodial, drimenol, isonordrimenone, and nordrimenone against the causative agents of bacterial canker (Clavibacter michiganensis) and bacterial speck (Pseudomonas syringae pv. tomato) on tomato crops [25]. Moreover, the same compounds showed important antimycotic activity against Fusarium oxysporum and Phytophthora spp. (tomato pathogens) with MIC $=64 \mu \mathrm{g} / \mathrm{mL}$ [25].

The high antimicrobial activity of the sesquiterpenes reported by several authors led to a Structure-Activity Relationships analysis of a series of 17 drimanes, supported by conformational and electronic studies, which allowed to show that the $\Delta^{7,8}$-double bond would be the main structural feature related to the antifungal activity [26]. These results could support our findings related to the activity of polygodial and its presence in the EtOAc extract of P. acuminata as the bioactive marker.

Inspired by previous studies over fresh fruits performed by other authors [27] and adapting the methodologies to our experiments, we successfully evaluated the action of $P$. acuminata extract containing $0.13 \mathrm{mg}$ of polygodial $/ \mathrm{mg}$ of dry extract on oranges and peaches inoculated with $P$. digitatum and $M$. fructicola, respectively. Oranges exposed to commercial Imz were visibly infected at the same level as those treated with the extract, showing no statistically significant differences between both; furthermore, the infected area seemed to be smaller in the oranges treated with the extract than in those exposed to the commercial product. Moreover, the incidence of brown rot disease on fresh 'Red Globe' peaches were compared with the application of the commercial product $\mathrm{Cbz}$, through the determination of the sporulation index of the infected fruits. To that end, the extract was applied to wound-inoculated peaches by immersion in a $62.5 \mu \mathrm{g} / \mathrm{mL}$ solution and no statistically significant differences were appreciated between both treatments.

Further experiments that use more fruits and formulation adding adjuvants to improve the efficacy of the extract are proposed to be carried out. Moreover, the application of P. acuminata EtOAc extract on other types of fruit would be interesting to assay.

The experimental results suggest that the potencies of P. acuminata EtOAc extract, chemically characterized by its bioactive marker, and the commercial antifungal agents against the tested phytopathogens are not too different. Remarkably, primary cytotoxic experiments demonstrated the lower toxicity of the extract compared with the commercial 
fungicides at the tested concentrations. After all these findings, we suggest that this natural product should be considered as an excellent candidate for further development to treat fungal fruit diseases.

\section{Materials and Methods}

\subsection{Plant Material and Preparation of the Extracts}

Leaves from the adult stage of Persicaria acuminata were collected in March 2016 around the city of Puerto Gaboto (Santa Fe province, Argentina) in one of the arms of the Coronda River. The wild plants were identified by Professor Susana Gattuso from the National University of Rosario (UNR) and a voucher specimen was deposited at the Herbarium of the Vegetal Biology Area of UNR (uipacha 531-(2000)-Rosario, Argentina, code: UNR 1672).

Air-dried leaves (100 g) were mechanically powdered. Stems and roots were not used because it has been previously demonstrated that the antifungal compounds are only present in leaves [19]. The material was successively macerated $(3 \times 24 \mathrm{~h}$ each) with hexane (Hex), ethyl acetate (EtOAc) and methanol $(\mathrm{MeOH})$, with mechanical stirring. After filtration and evaporation, Hex (1.5 g), EtOAc (2.1 g), and $\mathrm{MeOH}(2.7 \mathrm{~g})$ crude extracts were obtained and stored in a freezer at $-4{ }^{\circ} \mathrm{C}$.

\subsection{Isolation and Chemical Characterization of Natural Compounds 1-3}

Compounds 1-3 were isolated from EtOAc extracts of leaves of P. acuminata. The isolation of the pure compounds was performed according to previously reported procedures [19-21]. Compounds 1-3 were identified by micromelting point, optical rotation, and spectroscopic data, including ${ }^{1} \mathrm{H}$ and ${ }^{13} \mathrm{C}$ Nuclear Magnetic Resonance and were compared with authentic samples obtained previously in our laboratory $[19,28]$ for polygodial (1) or with the literature data, for drimenol (2) and confertifolin (3) [29,30]. Chemical compound descriptions and spectroscopic data are presented in the Supplementary Material (Figures S1-S6 and S11).

\subsection{Quantification of Polygodial in the Most Active Extract}

The EtOAc extract was submitted to GC-MS using a Turbo Mass Perkin Elmer chromatograph, equipped with a fused silica gel column (SE-30 $25 \mathrm{~m} \times 0.22 \mathrm{~mm}$ ID) with He as carrier gas, coupled to a mass selective detector, film $0.25 \mu \mathrm{m}$, ionization energy $70 \mathrm{eV}$ with a temperature programmer of $70-200{ }^{\circ} \mathrm{C}$ at $10{ }^{\circ} \mathrm{C} / \mathrm{min}$; total time $30 \mathrm{~min}$. Polygodial (1) was identified by comparison of its retention time (17.81-17.82 min) and the Mass Spectroscopy spectrum with an authentic sample obtained from our previous work [19]. Chromatograms and MS spectra are presented in the Supplementary Material (Figures S7-S11).

Quantification of polygodial content was carried out using Gas ChromatographyMass Spectrometry that was first validated following the International Council for Harmonisation (ICH) guidelines (1996) [31]. Stock solutions were diluted to appropriate concentrations in order to construct a calibration curve of polygodial and calculate relative response factors.

Linearity and calibration curve: Linearity of polygodial calibration curve was established by calculating the slope, intercepts and $R^{2}$ coefficient. The regression equation $(\mathrm{y}=91400 \mathrm{x}$ $-113.2)$ and $R^{2}(0.996)$ showed good linearity response in the range 1000 to $31.2(\mu \mathrm{g} / \mathrm{mL})$. LOD and LOQ were found to be 0.008 and $0.023 \mu \mathrm{g} / \mathrm{mL}$.

Precision: Intra- and inter-day variability test was determined for three times within 1 day and 3 consecutive days at three different concentrations (low, medium, and high), respectively. Variations were expressed by the percentage of relative standard deviation (\% RSD), confirming the precision of the proposed method.

Accuracy: In total, three concentrations (low, medium and high) of pre-analyzed sample solutions were spiked with known quantities of the standard and injected in 
triplicate to perform recovery studies. The percentage recovery for polygodial was between 97.5 and $99.6 \%(\mathrm{RSD}<4 \%, n=3)$, confirming the accuracy of the proposed method.

\subsection{Antifungal Studies}

\subsubsection{Microorganisms and Media}

Monosporic strains of each fungus were obtained from fruits that exhibited the corresponding disease symptoms, and were morphologically characterized by the Mycology Reference Center (CEREMIC-CCC, Rosario, Argentina) and the National Institute of Agricultural Technology (INTA, EE San Pedro, Argentina). The strains of P. digitatum CCC-102, P. italicum CCC-101 and M. fructicola INTA-SP345, were grown on Petri dishes filled with the culture medium Potato Dextrose Agar (PDA) and incubated during 7 to 10 days at 20$25^{\circ} \mathrm{C}$ (as needed for the suitable growth of each one). The inoculum of spore suspensions were obtained according to the CLSI reported procedures and adjusted to $1 \times 10^{4}$ Colony Forming Units (CFU)/mL [24].

\subsubsection{In Vitro Susceptibility Tests}

The MIC values were determined by using broth microdilution techniques according to the CLSI guidelines [24] for filamentous fungi (document M38). Microtiter trays were incubated at $20-25^{\circ} \mathrm{C}$ in a moist dark chamber, and MIC values were visually recorded at a time according to the growth control of each fungus evaluated. For the assay, solutions of each extract/compound (50 mg/mL or $12.5 \mathrm{mg} / \mathrm{mL}$, respectively) were prepared in Dimethylsulfoxide. Aliquots $(40 \mu \mathrm{L})$ of these were diluted in the liquid media Sabouraud $2 \times(960 \mu \mathrm{L})$ to obtain stock solutions that were serially diluted from 500 to $7.9 \mu \mathrm{g} / \mathrm{mL}$ (final volume $=100 \mu \mathrm{L}$ ) in the corresponding wells of a microtiter plate. A volume of fungal suspension $(100 \mu \mathrm{L})$ was added to each well, except for the sterility control, where sterile water was used instead. The commercial antifungal agents Imz and Cbz were used as positive controls. The MIC endpoints were defined as the lowest concentration of extract or compound, visually resulting in the total inhibition of the fungal growth compared to the growth in the control wells containing no antifungal agent.

The Minimum Fungicidal Concentration (MFC) was defined as the lowest concentration of extract or compound that fully killed the fungi. The MFC values were determined after assessing the corresponding MIC data, by transferring sample aliquots $(5 \mu \mathrm{L})$ from each clear well of the microtiter tray onto a 150-mm PDA plate. The inoculated plates were incubated at $20-25{ }^{\circ} \mathrm{C}$ and the MFC values were recorded after 7 to 10 days, according to the corresponding growth control. The evaluated samples were considered inactive when MIC or MFC resulted higher than $1000 \mu \mathrm{g} / \mathrm{mL}$ for extracts or higher than $250 \mu \mathrm{g} / \mathrm{mL}$ for pure compounds.

For bioautography, chromatograms performed in TLC plates using the mixture Hexane:EtOAc (7:3) as mobile phase were placed in sterile Petri dishes with cover. Potato Dextrose growth media with $0.6 \%$ agar and $0.02 \%$ phenol red containing an inoculum of M. fructicola of $1 \times 10^{4} \mathrm{CFU} / \mathrm{mL}$, quantified according to reported procedures [32], was distributed over the TLC plate $\left(1 \mathrm{~mL} / \mathrm{cm}^{2}\right)$ containing the samples $(15 \mu \mathrm{g}$ of the hexanic and EtOAc extracts and $5 \mu \mathrm{g}$ of the pure compound). After solidification of the media, the TLC plates were incubated for 6 days at $20^{\circ} \mathrm{C}$. Subsequently, bioautograms were sprayed with an aqueous solution $(1 \mathrm{mg} / \mathrm{mL})$ of methylthiazolyltetrazolium chloride (MTT) and incubated for another $3 \mathrm{~h}$ at $20^{\circ} \mathrm{C}$. Dark yellow inhibition zones appeared against a dark brown background [33].

4.4.3. Ex Vivo Antifungal Assays Using P. acuminata Chemically Characterized Extract on Wounded Fruits

Oranges (cv. 'Salustiana') and peaches (cv. 'Red Globe') were harvested from the Experimental Field of Intensive and Forestry Crops (Facultad de Ciencias Agrarias, Universidad Nacional de Litoral) at the mature stage and sorted based on size and absence of physical injuries or disease infection. No post-harvest commercial fungicide treatments 
had been applied before the fruits were collected. The oranges and peaches were cleaned and surface-disinfected with $2 \%(w / v)$ sodium hypochlorite for $3 \mathrm{~min}$, rinsed with tap water, and then air-dried. Once treated with the fungicides proposed in this work, the fruits were put in 3 plastic boxes of $300 \mathrm{~mm} \times 500 \mathrm{~mm} \times 100 \mathrm{~mm}$ covered in the bottom with filter papers embedded with $25 \mathrm{~mL}$ of sterile water in order to maintain a high relative humidity (90-95\%). Each plastic box contained the fruit units that had been submitted to the same treatment: negative control using commercial fungicide, positive control using sterile water, or $P$. acuminata extract solution as the alternative fungicide.

The fruits were stored at $20^{\circ} \mathrm{C}$ for 14 days (oranges) or 10 days (peaches) in accordance with the disease evolution of the control sets. After storage, the degree of P. digitatum (for oranges) or M. fructicola (for peaches) sporulation on the surface of decayed fruits was evaluated on a 0 to 4 scale (sporulation index). In this scale, the incidence and severity of the disease were visually quantified assuming the following values: 0 (negligible sporulation); 1 (fruits with lesions up to $10 \%$ of its surface); 2 (fruits with injuries between 10 and $30 \%$ of its surface); 3 (fruits with lesions between 30 and $50 \%$ of its surface) and 4 (refers to a dense fungal sporulation over the entire fruit that infected in more than $50 \%$ of its surface). The index value for each fruit was treated as a replicate, and each treatment mean was subjected to statistical analysis $[27,34,35]$.

For the trial with oranges, each fruit was wounded ( $3 \mathrm{~mm}$ deep and $3 \mathrm{~mm}$ wide) with a sterile nail in the top of the fruit and $10 \mu \mathrm{L}$ of a conidial suspension $\left(10^{5} \mathrm{CFU} / \mathrm{mL}\right)$ of $P$. digitatum was placed into each wound. Once inoculated, the fruits were randomly distributed into 3 groups with 10 units each: one group was submitted to a treatment with EtOAc extract of P. acuminata $(250 \mu \mathrm{g} / \mathrm{mL})$ according to the results obtained by the in vitro antifungal assay; while the other groups were used as negative control (sterile water treatment) and positive control employing commercial Imz at $7.8 \mu \mathrm{g} / \mathrm{mL}$, according also to the in vitro assay result. The treatments were carried out after $2 \mathrm{~h}$ of inoculation, by immersion during $3 \mathrm{~s}$ of each fruit into a beaker with the corresponding solutions mentioned above.

For the trial with peaches, each fruit was wounded with a sterile tip in the upper zone and $10 \mu \mathrm{L}$ of a conidial suspension $\left(10^{5} \mathrm{CFU} / \mathrm{mL}\right)$ of $M$. fructicola was placed into each wound. Once inoculated, the fruits were randomly distributed into 3 groups with 10 units each: one group was submitted to a treatment with EtOAc extract of P. acuminata $(62.5 \mu \mathrm{g} / \mathrm{mL})$ according to the results obtained by the in vitro antifungal assay; while the other groups were used as negative control (sterile water treatment) and positive control employing commercial $\mathrm{Cbz}$ at $1.9 \mu \mathrm{g} / \mathrm{mL}$, according also to the in vitro assay result. The treatments were carried out after $4 \mathrm{~h}$ of inoculation, by immersion during $3 \mathrm{~s}$ of each fruit into a beaker with the corresponding solutions mentioned above.

Statistical Analysis: Experimental data were analyzed statistically by one-way ANOVA followed by Tukey's multiple comparison test $(\alpha=0.05)$ using the GraphPad Prism 7.0 software.

\subsection{Cell Viability Assay}

Human hepatoma (Huh7) cells were treated for $24 \mathrm{~h}$ with different concentrations of EtOAc extract of P. acuminata, Imz and Cbz $\left(2 \times, 1 \times, \frac{1}{2} \times\right.$ and $\frac{1}{4} \times$ MIC) and the cell viability was estimated by the MTT assay [36]. Experiments were done by triplicate and mean followed by standard deviation were calculated. As a positive control (100\% death), $10 \%$ DMSO was used as the starting dilution, and the reading for all the dilutions was considered $0 \%$ viability. As a negative control ( $0 \%$ death), $0.1 \%$ DMSO was used, and the reading for all the dilutions was considered $100 \%$ viability.

Supplementary Materials: The following are available online at https:/ /www.mdpi.com/2223-7 747/10/3/425/s1. Figure S1: ${ }^{1} \mathrm{H}$ NMR spectra of polygodial (1). Figure S2: ${ }^{13} \mathrm{C}$ NMR spectra of polygodial (1). Figure S3: ${ }^{1} \mathrm{H}$ NMR spectra of drimenol (2). Figure $S 4{ }^{13} \mathrm{C}$ NMR spectra of drimenol (2). Figure S5 ${ }^{1} \mathrm{H}$ NMR spectra of confertifolin (3). Figure S6: ${ }^{13} \mathrm{C}$ NMR spectra of confertifolin (3). Figure S7: Gas chromatogram and Total Ion Chromatogram (TIC) area obtained for $0.5 \mathrm{mg} / \mathrm{mL}$ 
solution of polygodial (1). Figure S8: Gas chromatogram and Total Ion Chromatogram (TIC) area obtained for $0.25 \mathrm{mg} / \mathrm{mL}$ solution of polygodial (1). Figure S9: Gas chromatogram and Total Ion Chromatogram (TIC) area obtained for $0.125 \mathrm{mg} / \mathrm{mL}$ solution of polygodial (1). Figure S10: Gas chromatogram and Total Ion Chromatogram (TIC) area obtained for Ethyl Acetate extract of $P$. acuminata $(1 \mathrm{mg} / \mathrm{mL})$. Figure S11: Mass spectrum of pure polygodial (1).

Author Contributions: Conceptualization, L.A.S. and M.G.D.; methodology, V.E.R., L.N.F., M.G.D.L., and G.M.S.; software, M.G.D.L. and G.M.S.; validation, M.G.D.L. and G.M.S.; formal analysis, L.A.S. and M.G.D.; investigation, M.G.D.L., G.M.S., and L.N.F.; resources, L.A.S., V.E.R., and M.G.D.; writing—original draft preparation, M.G.D.; writing—review and editing, L.A.S. and M.G.D.; supervision, L.A.S., V.E.R., and M.G.D.; project administration, L.A.S., V.E.R., and M.G.D.; funding acquisition, L.A.S., V.E.R., and M.G.D. All authors have read and agreed to the published version of the manuscript.

Funding: This research was funded by Consejo Nacional de Investigaciones Científicas y Técnicas (CONICET, PIP N ${ }^{\circ}$ 24) and Agencia Nacional de Promoción Científica y Tecnológica (ANPCyT, PICT 2015-2259).

Institutional Review Board Statement: Not applicable.

Informed Consent Statement: Not applicable.

Acknowledgments: M.G.D.L., G.M.S., and L.N.F. thank CONICET for their fellowships. All the authors greatly acknowledge to Susana Gatusso and Ariel Darío Quiroga for technical support during the collection and identification of the plant species and the performance of the cytotoxicity assays, respectively.

Conflicts of Interest: The authors declare no conflict of interest. The funders had no role in the design of the study; in the collection, analyses, or interpretation of data; in the writing of the manuscript, or in the decision to publish the results.

\section{References}

1. Pergomet, J.L.; Di Liberto, M.G.; Derita, M.G.; Bracca, A.B.J.; Kaufman, T.S. Activity of the pterophyllins 2 and 4 against postharvest fruit pathogenic fungi. Comparison with synthetic analog and related intermediates. Fitoterapia 2018, 125, 98-105. [CrossRef] [PubMed]

2. Cortés, I.; Di Liberto, M.G.; Kaufman, T.S.; Derita, M.G.; Bracca, A.B.J. Synthesis and evaluation of aromatic methoxime derivatives against five postharvest phytopathogenic fungi of fruits. Main structure-activity relationships. Food Chem. 2020, $321,126701$. [CrossRef]

3. Fu, W.; Tian, G.; Pei, Q.; Ge, X.; Tian, P. Evaluation of berberine as a natural compound to inhibit peach brown rot pathogen. Crop. Prot. 2017, 91, 20-26.

4. Zhang, Y.; Zeng, L.; Yang, J.; Zheng, X.; Yu, T. 6-Benzylaminopurine inhibits growth of Monilinia fructicola and induces defenserelated mechanism in peach fruit. Food Chem. 2015, 187, 210-217. [CrossRef] [PubMed]

5. Novaes Azevedo, A.; Ribeiro Buarque, P.; Oliveira Cruz, E.M.; Fitzgerald Blank, A.; Linsde Aquino, L. Response surface methodology for optimization of edible chitosan coating formulations incorporating essential oil against several food borne pathogenic bacteria. Food Control. 2014, 43, 1-9. [CrossRef]

6. Di Liberto, M.G.; Stegmayer, M.I.; Svetaz, L.A.; Derita, M.G. Evaluation of Argentinean medicinal plants and isolation of their bioactive compounds as an alternative for the control of postharvest fruits phytopathogenic fungi. Rev. Bras. Farmacogn. 2019, 29, 686-688. [CrossRef]

7. Stegmayer, M.I.; Álvarez, N.H.; Favaro, M.A.; Fernandez, L.N.; Carrizo, M.E.; Reutemann, A.G.; Derita, M.G. Argentinian Wild Plants as Controllers of Fruits Phytopathogenic Fungi: Trends and Perspectives. In Wild Plants: The Treasure of Natural Healers; Rai, M., Bhattarai, S., Feitosa, C., Eds.; CRC Press: Boca Raton, FL, USA, 2020; Volume 1, pp. 121-137.

8. Di Liberto, M.G.; Caldo, A.; Quiroga, A.D.; Riveira, M.J.; Derita, M.G. Zanthosimuline and related pyranoquinolines as antifungal agents for postharvest fruit disease control. ACS Omega 2020, 5, 7481-7487. [CrossRef] [PubMed]

9. Macarisin, D.; Cohen, L.; Eick, A.; Rafael, G.; Belausov, E.; Wisniewski, M.; Droby, S. Penicillium digitatum suppresses production of hydrogen peroxide in host tissue during infection of citrus fruit. Phytopathology 2007, 97, 1491-1500. [CrossRef] [PubMed]

10. Sukorini, H.; Sangchote, S.; Khewkhom, N. Control of postharvest green mold of citrus fruit with yeasts, medicinal plants, and their combination. Postharvest Biol. Technol. 2013, 79, 24-31. [CrossRef]

11. Papoutsis, K.; Mathioudakis, M.M.; Hasperué, J.H.; Ziogas, V. Non-chemical treatments for preventing the postharvest fungal rotting of citrus caused by Penicillium digitatum (green mold) and Penicillium italicum (blue mold). Trends Food Sci. Technol. 2019, 86, 479-491. [CrossRef] 
12. Mondino, P. Sintomatología, etiología y características epidemiológicas de la enfermedad. In Manejo de la Podredumbre Morena (Monilinia fructicola y M. laxa) en Huertos Frutales de Uruguay, Chile, Bolivia, Brasil y Argentina; Mitidieri, M., Castillo, J.A., Eds.; CYTED Programa Interamericano de Ciencia y Tecnología para el Desarrollo: Madrid, Spain, 2014; Volume 2, pp. 35-41.

13. Dowling, M.E.; Bridges, W.C.; Cox, B.M.; Sroka, T.; Wilson, J.R.; Schnabel, G. Preservation of Monilinia fructicola genotype diversity within fungal cankers. Plant Dis. 2019, 103, 526-530. [CrossRef]

14. Mitidieri, M.S. Manejo Integrado de la Podredumbre Morena en Duraznero y Nectarinos. In Manejo de la Podredumbre Morena (Monilinia fructicola y M. laxa) en Huertos Frutales de Uruguay, Chile, Bolivia, Brasil y Argentina; Mitidieri, M., Castillo, J.A., Eds.; CYTED Programa Interamericano de Ciencia y Tecnología para el Desarrollo: Madrid, Spain, 2014; Volume 2, pp. 47-62.

15. Tran, T.T.; Li, H.; Nguyen, D.Q.; Jones, M.G.K.; Sivasithamparam, K.; Wylie, S.J. Monilinia fructicola and Monilinia laxa isolates from stone fruit orchards sprayed with fungicides displayed a broader range of responses to fungicides than those from unsprayed orchards. Eur. J. Plant Pathol. 2019, 153, 985-999. [CrossRef]

16. The Plant List. Available online: www.theplantlist.org (accessed on 11 November 2019).

17. Schmeda-Hirschmann, G.; Rojas de Arias, A. A screening method for natural products on triatomine bugs. Phytother. Res. 1992, 62, 68-73. [CrossRef]

18. Chiappeta, A.; de Melo, J.F.; Maciel, G. Higher plants with biological activity Plants of Pernambuco. Rev. Inst. Antibiot. 1983, $21,43-50$.

19. Derita, M.; Leiva, M.; Zacchino, S. Influence of plant part, season of collection and content of the main active constituent, on the antifungal properties of Polygonum acuminatum Kunth. J. Ethnopharmacol. 2009, 124, 377-383. [CrossRef] [PubMed]

20. Derita, M.; Zacchino, S. Chemotaxonomic importance of sesquiterpenes and flavonoids in Argentinian species of Polygonum genus. J. Essent. Oil Res. 2011, 23, 11-14. [CrossRef]

21. Derita, M.; Zacchino, S. Validation of the ethnopharmacological use of Polygonum persicaria for its antifungal properties. Nat. Prod. Commun. 2011, 6, 931-933. [CrossRef]

22. Shen, B.; Yang, I.; Yasamin, S.; Liang, N.A.; Su, W.; Chen, S.; Wang, X.; Wang, W. Analysis of the phytochemistry and bioactivity of the genus Polygonum of Polygonaceae. Digit. Chin. Med. 2018, 1, 19-36. [CrossRef]

23. Mahmoudi, M.; Boughalleb, F.; Bouhamda, T.; Abdellaoui, R.; Nasri, N. Unexploited Polygonum equisetiforme seeds: Potential source of useful natural bioactive products. Ind. Crop. Prod. 2018, 122, 349-357. [CrossRef]

24. Clinical and Laboratory Standards Institute (CLSI). Reference Method for Broth Dilution Antifungal Susceptibility Testing of Filamentous Fungi. CLSI Standard M38, 3rd ed.; CLSI: Wayne, PA, USA, 2017; pp. 1-35.

25. Montenegro, I.; Madrid, M.; Cuellar, M.; Seeger, M.; Alfaro, J.; Besoain, J.; Martínez, J.; Ramírez, I.; Olguín, Y.; Valenzuela, M. Biopesticide activity from drimanic compounds to control tomato pathogens. Molecules 2018, 23, 2053. [CrossRef]

26. Derita, M.; Montenegro, I.; Garibotto, F.; Enriz, R.; Cuellar Fritis, M.; Zacchino, S. Structural requirements for the antifungal activities of natural drimane sesquiterpenes and analogues, supported by conformational and electronic studies. Molecules 2013, 18, 2029-2051. [CrossRef]

27. Vilanova, L.; Teixidó, N.; Torres, R.; Usall, J.; Viñas, I.; Sánchez-Torres, P. Relevance of the transcription factor PdSte12 in Penicillium digitatum conidiation and virulence during citrus fruit infection. Int. J. Food Microbiol. 2016, 235, 93-102. [CrossRef]

28. Malheiros, A.; Cechinel Filho, V.; Schmitt, C.; Yunes, R.; Escalante, A.; Svetaz, L.; Zacchino, S.; Delle Monache, F. Antifungal activity of drimane sesquiterpenes from Drimys brasiliensis using bioassay-guided fractionation. J. Pharm. Pharm. Sci. 2005, 8, 335-339.

29. Hueso-Rodríguez, J.; Rodríguez, B. A new and efficient route to optically active drimanes. Synthesis of (+)-winterin, (+)confertifolin, (+)-isodrimenin and (+)-bicyclofarnesol. Tetrahedron 1989, 45, 1567-1576. [CrossRef]

30. Appel, H.; Bond, R.; Overton, K. The constitution and stereochemistry of valdiviolide, fuegin, winterin and futronolide. Tetrahedron 1963, 19, 635-641. [CrossRef]

31. ICH (International Conference on Harmonization). ICH Topic-Q2B Validation of Analytical Procedures: Methodology, Step 4, Consensus Guidelines. 1996. Available online: www.emea.eu.int/pdfs/human/ich/028195en.pdf (accessed on 26 May 2020).

32. Rahalison, L.; Hamburger, M.; Hostettmann, K.; Monod, M.; Frenk, E. A bioautographic agar overlay method for the detection of antifungal compounds from higher plants. Phytochem. Anal. 1991, 2, 199-203. [CrossRef]

33. Saxena, G.; Farmer, S.; Towers, G.H.N.; Hancock, R.E.W. Use of specific dyes in the detection of antimicrobial compounds from crude plant extracts using a thin layer chromatography agar overlay technique. Phytochem. Anal. 1995, 6, 125-129. [CrossRef]

34. Badawy, M.E.I.; Rabea, E.I. Potential of the biopolymer chitosan with different molecular weights to control postharvest gray mold of tomato fruit. Postharvest Biol. Technol. 2009, 51, 110-117. [CrossRef]

35. Egüen, B.; Melgarejo, P.; de Cal, A. Sensitivity of Monilinia fructicola from Spanish peach orchards to thiophanate-methyl, iprodione, and cyproconazole: Fitness analysis and competitiveness. Eur. J. Plant Pathol. 2015, 141, 789-801. [CrossRef]

36. Ferretti, A.C.; Tonucci, F.M.; Hidalgo, F.; Almada, E.; Larocca, M.C.; Favre, C. AMPK and PKA Interaction in the Regulation of Survival of Liver Cancer Cells Subjected to Glucose Starvation. Oncotarget 2016, 7, 17815-17828. [CrossRef] 